\title{
Sensitivity of $\mathrm{Nb}_{3} \mathrm{Sn}$ Rutherford-type Cables to Transverse Pressure
}

\author{
E. Barzi, T. Wokas, A. V. Zlobin
}

\begin{abstract}
Fermilab is developing high field superconducting magnets for future accelerators based on $\mathrm{Nb}_{3} \mathrm{Sn}$ strands. Testing the critical current of superconducting cables under compression is a means to appraise the performance of the produced magnet. However, these cable tests are expensive and labor-intensive. A fixture to assess the superconducting performance of a $\mathrm{Nb}_{3} \mathrm{Sn}$ strand within a reacted and impregnated cable under pressure was designed and built at Fermilab. Several Rutherford-type cables were fabricated at Fermilab and at LBNL using multifilamentary $\mathrm{Nb}_{3} \mathrm{Sn}$ strands. The sensitivity of $\mathrm{Nb}_{3} \mathrm{Sn}$ to transverse pressure was measured for a number of $\mathrm{Nb}_{3} \mathrm{Sn}$ technologies (Modified Jelly Roll, Powder-in-Tube, Internal Tin, and Restack Rod Process). Results on the effect of a stainless steel core in the cable are also shown.
\end{abstract}

Index Terms-Rutherford cable, $\mathrm{Nb}_{3} \mathrm{Sn}$, transverse pressure, critical current.

\section{INTRODUCTION}

$\mathrm{T}$ HE critical current, $I_{c}$, of a $\mathrm{Nb}_{3} \mathrm{Sn}$ virgin strand is reduced during magnet fabrication and operation. In addition to cabling, cable compression in the coil due to precompression, cool-down and Lorenz force decrease the original $\mathrm{I}_{\mathrm{c}}$. This is due to $J_{c}$ sensitivity of $\mathrm{Nb}_{3} \mathrm{Sn}$ to strain. Previous work on transverse stress effect in earlier $\mathrm{Nb}_{3} \mathrm{Sn}$ materials includes [1][3]. The device herein described allows providing quantitative information on the $I_{c}$ degradation occurring under stress in a $\mathrm{Nb}_{3} \mathrm{Sn}$ superconducting (SC) magnet in a very inexpensive way, i.e. with strand tests as opposed to cable tests, and by using the existent Short Sample Test Facility (SSTF) at Fermilab. This is as much more convenient as recent $I_{c}$ data obtained in cable tests have shown an excellent correlation with strand measurements [4].

To reproduce the real conditions in which the superconductor will operate in the magnet, the pressure is applied to the strand within a Rutherford cable. To prevent current sharing, the housing cable is made of $\mathrm{Cu}$. An impregnation fixture that is used also for reaction was designed. The cable sample is stacked with a $\mathrm{Cu}$ cable, and the two are reacted and impregnated together to improve pressure distribution during testing.

Manuscript received October 5, 2004. This work was supported by the U.S. Department of Energy.

All authors are with the Fermi National Accelerator Laboratory, Batavia, IL 60510 USA (corresponding author: 630-840-3446; fax: 630-840-2383; email: barzi@fnal.gov).

\section{EXPERIMENTAL PROCEDURE}

\section{A. Test Device}

The test device is shown in Fig. 1 and a more detailed description can be found in [5]. The cable sample (1) is compressed between two Inconel plates. The bottom plate (2), made of two spherically coupled parts, is driven up by an Inconel rod assembly (3), which is pulled up by a 20 ton hydraulic cylinder placed on a stainless steel support on the top flange of the device. The top plate (4) is welded to an Inconel tube (5), which is itself welded to the top flange. The assembly is immersed in boiling $\mathrm{He}$ at $4.2 \mathrm{~K}$ within the $64 \mathrm{~mm}$ bore of a superconducting solenoid. The device was designed such as to center the cable sample within the solenoid. The copper leads were designed to carry currents of up to $2000 \mathrm{~A}$. After reaction and impregnation, the cable sample is carefully mounted at the bottom of the device by soldering the ends of a strand to the current leads. The strand ends are long enough to ensure current transfer. To allow for the differential thermal contraction between copper and Inconel, the current leads are free to move vertically within a bellows at the top of the device. To decouple the rod motion from the current leads, another smaller bellows is used.

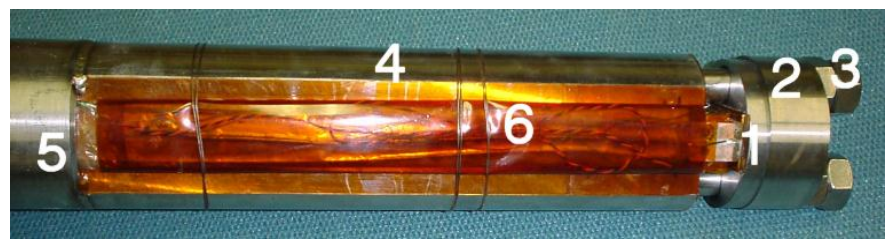

Fig. 1. Test device.

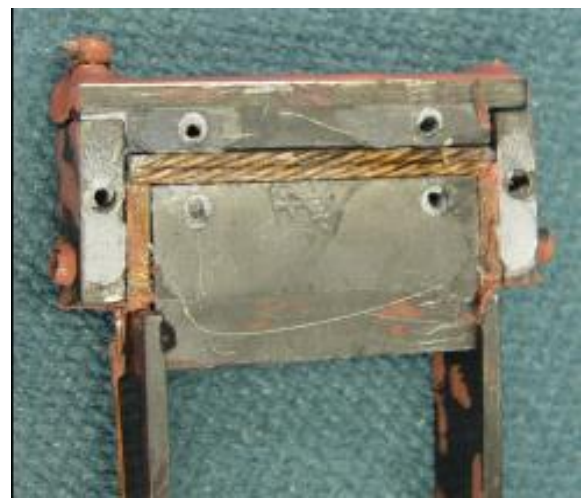

Fig. 2. Reaction/impregnation fixture after impregnation and removal of the side plates. 


\section{B. Sample Preparation}

To prevent current sharing, cable samples were prepared by extracting a strand from a piece of SC Rutherford cable and inserting it in place of a $\mathrm{Cu}$ strand within a shorter piece of cable $14.24 \mathrm{~mm}$ wide and $1.8 \mathrm{~mm}$ thick, made of $\mathrm{Cu}$ strands. A $\mathrm{Cu}$ cable with SS core is used to study its effect on pressure sensitivity. One edge of the extracted strand is placed in the middle of the housing cable. The ends of the selected strand are $20 \mathrm{~cm}$ to ensure current transfer once soldered to the current leads. A single fixture was designed for both reaction and impregnation in order to limit handling of the sample after reaction. This fixture, opened, is shown in Fig. 2. After reaction in argon atmosphere, the sample is delicately removed from the fixture in order to spray the latter with mold release. The sample is carefully replaced in the fixture, and two small copper plates are soldered to the strand to reinforce the bends. The fixture is then closed for impregnation with CTD epoxy.

\section{Measurement Procedure}

After applying very slowly the desired load by means of a Power Team hydraulic cylinder supplied by an Enerpack pump, the voltage-current (VI) characteristics were measured in boiling $\mathrm{He}$ at $4.2 \mathrm{~K}$, in a transverse magnetic field, $\mathrm{B}$, between 10 and $14 \mathrm{~T}$. The voltage was measured at the ends of the cable sample by voltage taps placed $53 \mathrm{~mm}$ apart, just outside the cable length. The sample critical current $I_{c}$ was determined from the VI curve using the backward extrapolation criterion. An additional pair of voltage taps was placed on the strand tails to ensure sample protection. To counteract the lateral Lorentz force generated by the relative directions of magnetic field and transport current, two thin G10 wings were placed at the sides of the sample through holes around the bottom rods. The estimated uncertainty of the $\mathrm{I}_{\mathrm{c}}$ measurements in this study is within $\pm 5 \%$. Tests were carried out at pressures up to $200 \mathrm{MPa}$.

TABLE I

Parameters of Tested Cable Samples

\begin{tabular}{|c|c|c|c|c|c|c|c|c|c|c|c|c|c|c|c|}
\hline \multicolumn{5}{|c|}{ Powder-in-Tube } & \multicolumn{5}{|c|}{ Modified Jelly Roll } & \multicolumn{3}{|c|}{ Internal Tin } & \multicolumn{3}{|c|}{ Restack Rod Process } \\
\hline $\begin{array}{c}\text { Billet } \\
\text { No }\end{array}$ & $\begin{array}{l}\text { HT } \\
\text { No }\end{array}$ & $\begin{array}{c}\mathrm{PF}, \\
\%\end{array}$ & $\begin{array}{c}\text { Fabricate } \\
\mathrm{d} \\
\text { w/core }\end{array}$ & $\begin{array}{l}\text { Tested } \\
\text { w/core }\end{array}$ & $\begin{array}{c}\text { Billet } \\
\text { No }\end{array}$ & $\begin{array}{l}\text { HT } \\
\text { No }\end{array}$ & $\begin{array}{c}\mathrm{PF}, \\
\%\end{array}$ & $\begin{array}{c}\text { Fabricate } \\
d \\
\text { w/core }\end{array}$ & $\begin{array}{l}\text { Tested } \\
\text { w/core }\end{array}$ & $\begin{array}{c}\mathrm{PF}, \\
\%\end{array}$ & $\begin{array}{c}\text { Fabricate } \\
\text { d } \\
\text { w/core }\end{array}$ & $\begin{array}{l}\text { Tested } \\
\text { w/core }\end{array}$ & $\begin{array}{c}\mathrm{PF}, \\
\%\end{array}$ & $\begin{array}{c}\text { Fabricate } \\
d \\
\text { w/core }\end{array}$ & $\begin{array}{l}\text { Tested } \\
\text { w/core }\end{array}$ \\
\hline 151 & $\bar{A}$ & 85.6 & $\mathrm{Y}$ & $\mathrm{N}$ & 113 & $\mathrm{D}$ & 87.3 & $\mathrm{~N}$ & $\mathrm{~N}$ & 88.6 & $\mathrm{~N}$ & $\mathrm{~N}$ & 88.5 & $\mathrm{~N}$ & $\mathrm{~N}$ \\
\hline 151 & B & 89.5 & $\mathrm{Y}$ & Y & 113 & $\mathrm{D}$ & 88.5 & $\mathrm{~N}$ & $\mathrm{~N}$ & 89.5 & $\mathrm{Y}$ & $\mathrm{N}$ & & & \\
\hline 151 & B & 91.5 & $\mathrm{Y}$ & Y & 187 & $\mathrm{D}$ & 86.6 & Y & $\mathrm{N}$ & 89.5 & $\mathrm{Y}$ & $\mathrm{Y}$ & & & \\
\hline 159 & $\mathrm{C}$ & 86.7 & $\mathrm{~N}$ & $\mathrm{~N}$ & 187 & $\mathrm{E}$ & 88.4 & Y & Y & & & & & & \\
\hline 159 & $\mathrm{C}$ & 88.6 & $\mathrm{~N}$ & $\mathrm{~N}$ & & & & & & & & & & & \\
\hline 181 & $\mathrm{C}$ & 89.5 & $\mathrm{~N}$ & $\mathrm{Y}$ & & & & & & & & & & & \\
\hline & & & & & & & & & & & Duration, $\mathrm{h}$ & & 100 & 48 & 72 \\
\hline
\end{tabular}

TABLE II

PARAMETERS OF THE STRANDS USED IN THE CABLE S

\begin{tabular}{|c|c|c|c|c|c|c|c|}
\hline $\begin{array}{c}\text { Strand } \\
\text { Parameter }\end{array}$ & PIT 151 & PIT 159 & PIT 181 & MJR 113 & MJR 187 & $\begin{array}{c}\text { IT } \\
\text { (ITER- } \\
\text { type) }\end{array}$ & RRP \\
\hline $\begin{array}{c}\text { Strand } \\
\text { diameter, } \\
\mathrm{mm}\end{array}$ & 1.000 & 1.000 & 1.000 & 1.000 & 1.000 & 1.000 & 0.700 \\
\hline $\mathrm{I}_{\mathrm{c}}(12 \mathrm{~T}), \mathrm{A}$ & $\sim 620$ & $\sim 720$ & $\sim 780$ & $\sim 700$ & $\sim 900$ & $\sim 200$ & $>500$ \\
\hline $\mathrm{d}_{\mathrm{eff}}, \mu \mathrm{m}$ & $\sim 50$ & $\sim 50$ & $\sim 50$ & $\sim 110$ & $\sim 110$ & $\sim 5$ & $\sim 80$ \\
\hline $\mathrm{Cu}, \%$ & 48.7 & 54.8 & 53.6 & 47.8 & 46.7 & 58.7 & 50.0 \\
\hline $\begin{array}{c}\text { Twist } \\
\text { pitch, } \\
\text { mm/turn }\end{array}$ & 20 & 20 & 20 & 23 & 23 & 13 & 12 \\
\hline
\end{tabular}

TABLE III

Heat TREatment CyCles

\begin{tabular}{|c|c|c|c|c|c|}
\hline \multicolumn{3}{|c|}{ Heat Treatment } & Step 1 & Step 2 & Step 3 \\
\hline \multirow{3}{*}{ A } & \multirow{3}{*}{ PIT } & Ramp rate, ${ }^{\circ} \mathrm{C} / \mathrm{h}$ & 25 & & \\
\hline & & Temperature, ${ }^{\circ} \mathrm{C}$ & 700 & & \\
\hline & & Duration, $\mathrm{h}$ & 60 & & \\
\hline \multirow{3}{*}{ B } & \multirow{3}{*}{ PIT } & Ramp rate, ${ }^{\circ} \mathrm{C} / \mathrm{h}$ & 25 & & \\
\hline & & Temperature, ${ }^{\circ} \mathrm{C}$ & 655 & & \\
\hline & & Duration, $\mathrm{h}$ & 170 & & \\
\hline \multirow{3}{*}{$\mathrm{C}$} & \multirow{3}{*}{ PIT } & Ramp rate, ${ }^{\circ} \mathrm{C} / \mathrm{h}$ & 25 & 50 & 75 \\
\hline & & Temperature, ${ }^{\circ} \mathrm{C}$ & 210 & 340 & 675 \\
\hline & & Duration, $\mathrm{h}$ & 168 & 40 & 65 \\
\hline \multirow{3}{*}{$\mathrm{D}$} & \multirow{3}{*}{ MJR, IT } & Ramp rate, ${ }^{\circ} \mathrm{C} / \mathrm{h}$ & 25 & 50 & 75 \\
\hline & & Temperature, ${ }^{\circ} \mathrm{C}$ & 210 & 340 & 700 \\
\hline & & Duration, $\mathrm{h}$ & 48 & 48 & 40 \\
\hline \multirow[b]{2}{*}{$\mathrm{E}$} & & Ramp rate, ${ }^{\circ} \mathrm{C} / \mathrm{h}$ & 25 & 50 & 75 \\
\hline & MJR, RRP & Temperature, ${ }^{\circ} \mathrm{C}$ & 210 & 340 & 650 \\
\hline
\end{tabular}

\section{Strand and Cable Description}

The parameters of the samples that were tested are shown in Table I. For completeness are included data from [6]. The PIT, MJR 113 and IT cables were fabricated at FNAL, whereas the MJR 187 and RRP cables were fabricated at LBNL. All cables but the RRP's are 28-strand keystoned with the same pitch length of about $110 \mathrm{~mm}$, corresponding to a transposition angle of $14.5 \pm 0.1$ degrees. The packing factor was varied by modifying the cable mean thickness, whereas cable width and keystone angle were kept within $14.24 \pm 0.025 \mathrm{~mm}$ and $0.91 \pm 0.1$ degrees respectively. The RRP cables are 39 -strand rectangular and keystoned with a pitch length of $111 \mathrm{~mm}$, corresponding to the same transposition angle of $14.5 \pm 0.1$ degree. For the keystoned cables, the keystone angle was $0.96 \pm 0.1$ degrees. The SS core material is $9.52 \mathrm{~mm}$ by 0.025 mm, 316-L annealed. Two different multifilamentary Modified Jelly Roll (MJR) $\mathrm{Nb}_{3}$ Sn strands and a Restack Rod Process (RRP) strand by Oxford Superconducting Technology (OST), three Powder-in-Tube (PIT) strands by ShapeMetal Innovation (SMI), and an IT of ITER-type design by Intermagnetics General Corporation (IGC) were used to manufacture the cables. These strands parameters are shown in Table II, and the heat treatment cycles used in Table III. 


\section{RESULTS AND DISCUSSION}

\section{A. IT Samples}

Fig. 3 shows $I_{c}$ as a function of transverse pressure at $12 \mathrm{~T}$ for the IT samples. The lines on the plot indicate load sequences. For instance, in the case in Figure, the load sequence for the IT $88.6 \%$ sample started at $27.9 \mathrm{MPa}$ to 83.6 , to 139.4 , back to 27.9 , to 147.8 , back to 27.9 , to 156.1 , back to 27.9 , to 167.3 , back to 27.9 , to 175.6 , back to 27.9 , to 175.6 , back to 27.9 , to 184 , back to 27.9 , to 195.2 , back to 27.9 , and to $195.2 \mathrm{MPa}$. This is typically done to pinpoint the minimum pressure at which irreversibility starts occurring. From these data it appears that in the case of IT cables without and without a core, $I_{c}$ degradation at $12 \mathrm{~T}$ is negligible and reversible up to about $140 \mathrm{MPa}$ of pressure. Irreversibility begins at pressures somewhat larger than this value, with a $5 \%$ residual degradation at about $150 \mathrm{MPa}$. However, at about 200 MPa of pressure, samples without a core show an $I_{c}$ degradation of 70 to $80 \%$ at $12 \mathrm{~T}$, most of which is maintained all along the unloading cycle down to $27.8 \mathrm{MPa}$. One can notice though that past $140 \mathrm{MPa}$ of pressure, the sample with core appears to degrade at half the rate of the samples without core. More statistics is needed to confirm this behavior is systematic. The results obtained on the IT samples could be compared with actual cable tests performed on 41-strand cables made of $0.7 \mathrm{~mm}$ IT strands and featuring a core [4]. This was done by plotting the $I_{c}$ normalized to that obtained at the lowest pressure, as shown in Fig. 4. One can notice a better consistency of the results at comparable fields in the case of samples with a core, as expected.

\section{B. MJR Samples}

Fig. 5 shows the critical currents normalized to those at minimum loads as a function of transverse pressure at $12 \mathrm{~T}$ for the MJR samples. As the first sample that was tested (lozenges) was loaded using large pressure steps, that did not allow accurate location of the onset of irreversibility (somewhere between 80 and $140 \mathrm{MPa}$ ), when testing the second sample (triangles), load steps were reduced in size. In this case the onset of irreversibility was found to be at around $140 \mathrm{MPa}$, and in any case below $150 \mathrm{MPa}$. After loading up to about $210 \mathrm{MPa}, I_{c}$ degradation was on the order of $80 \%$. Although these two samples showed an excellent reproducibility, the third sample that was tested behaved somewhat differently, showing a degradation of about $20 \%$ already at around $110 \mathrm{MPa}$. Past this value, the degradation rate was about the same as for the other samples. Again, more statistics are needed to understand if these differences are real.

\section{PIT Samples}

The normalized results at $12 \mathrm{~T}$ for the PIT samples are shown in Fig. 6. In the case of the samples without core, up to about $60 \mathrm{MPa}$ of pressure the $\mathrm{I}_{\mathrm{c}}$ degradation was found to be reversible for at least one sample, and smaller than $15 \%$ for all samples. The onset of irreversibility occurred beyond $60 \mathrm{MPa}$. However, at $100 \mathrm{MPa}$ the $\mathrm{I}_{\mathrm{c}}$ degradation was already about
$20 \%$ or larger for some samples, and appeared to rapidly increase at larger loads. After loading up to about $200 \mathrm{MPa}$, the $I_{c}$ degradation was on the order of $90 \%$, all of it permanent. However, whereas the best of the PIT samples without core featured $10 \%$ degradation already at $100 \mathrm{MPa}$, most of the samples with core showed a similar degradation at a load as large as $140 \mathrm{MPa}$. The only sample with core, PIT 181, that had a faster degradation rate at the beginning, eventually met the curve of PIT $15189.5 \%$ with core at about $150 \mathrm{MPa}$ with $30 \%$ degradation only, and then resumed the same degradation rate.

More data are needed to understand whether the spread observed in the results of these PIT cables are due to a few damaged samples or indicates a real physics phenomenon. This latter conclusion would be consistent with the variation observed in short sample limits of PIT coils made and tested at Fermilab [7].

\section{RRP Samples}

Until more statistics is gathered, caution is needed in interpreting Fig. 7 that shows results at 12 and $14 \mathrm{~T}$ of the only RRP sample that was tested. It seems that the degradation rate at $14 \mathrm{~T}$ is 4 to $6 \%$ larger than at $12 \mathrm{~T}$, but yet this is comparable with the measurement uncertainty.

\section{CONCLUSION}

These results obtained on sensitivity of $\mathrm{Nb}_{3} \mathrm{Sn}$ to transverse pressure already show solid consistency, as evidenced in Fig. 8 , where the normalized $I_{c}$ is plotted as a function of transverse pressure for all samples at $12 \mathrm{~T}$. It is using these data to take into account $I_{c}$ degradation due to the loads that short sample limit ranges for the PIT coils made at Fermilab could be appropriately and correctly calculated. The data obtained so far seem to indicate that a SS core helps reducing sensitivity to transverse pressure in $\mathrm{Nb}_{3} \mathrm{Sn}$ Rutherford cables. This has yet to be theoretically understood, and more data are needed to refine the present findings.

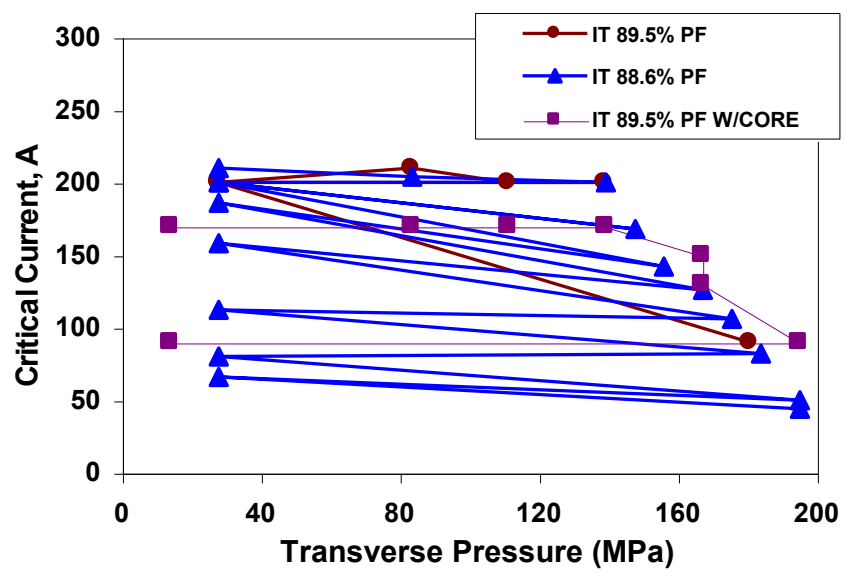

Fig. 3. $\mathrm{I}_{\mathrm{c}}$ vs. transverse pressure for the IT samples at $12 \mathrm{~T}$. 


\section{REFERENCES}

[1] C. Pasztor et al., "Transverse stress effects in $\mathrm{Nb}_{3} \mathrm{Sn}$ cables", IEEE Trans. on Magnetics, V. 30, No. 4, Jul. 1994, p. 1938.

[2] J. M. van Oort, "Critical current degradation in $\mathrm{Nb}_{3} \mathrm{Sn}$ superconductors in accelelerator magnets", Graduation Thesis, Feb. 2000, Twente University, Netherland.

[3] D. R. Dietderich et al., "Critical current of superconducting Rutherford cable in high magnetic fields with transverse pressure", IEEE Trans. Appl. Sup., V. 9, No. 2, June 1999, p. 122.

[4] P. Bauer et al., "Fabrication and testing of Rutherford cables for react and wind accelerator magnets", IEEE Trans. Appl. Sup., V. 11, No. 1, March 2001, p. 2457.

[5] E. Barzi , M. Fratini, and A. V. Zlobin, "A device to test critical current sensitivity of $\mathrm{Nb}_{3} \mathrm{Sn}$ to pressure", Advances in Cryogenic Engineering, V. 48A, p. 45, 2002.

[6] E. Barzi, T. Wokas, A. V. Zlobin, "Sensitivity of $\mathrm{Nb}_{3}$ Sn Rutherfordtype cables to transverse pressure". 6th European Conference on Applied Superconductivity (EUCAS 2003), Sept. 14-18, 2003, Sorrento, Italy.

[7] A. V. Zlobin et al., "'Development and Test of $\mathrm{Nb}_{3} \mathrm{Sn}$ Cos-theta Dipoles Based on PIT Strands", this conference $\underline{3 \mathrm{LG} 02}$.

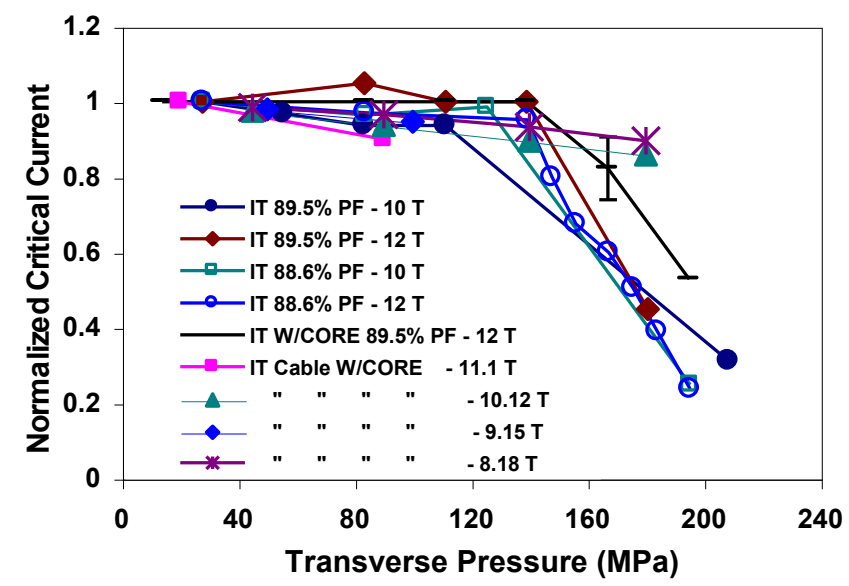

Fig. 4. Normalized $I_{c}$ vs. transverse pressure for the IT samples and comparison with results obtained on actual cable tests [4].

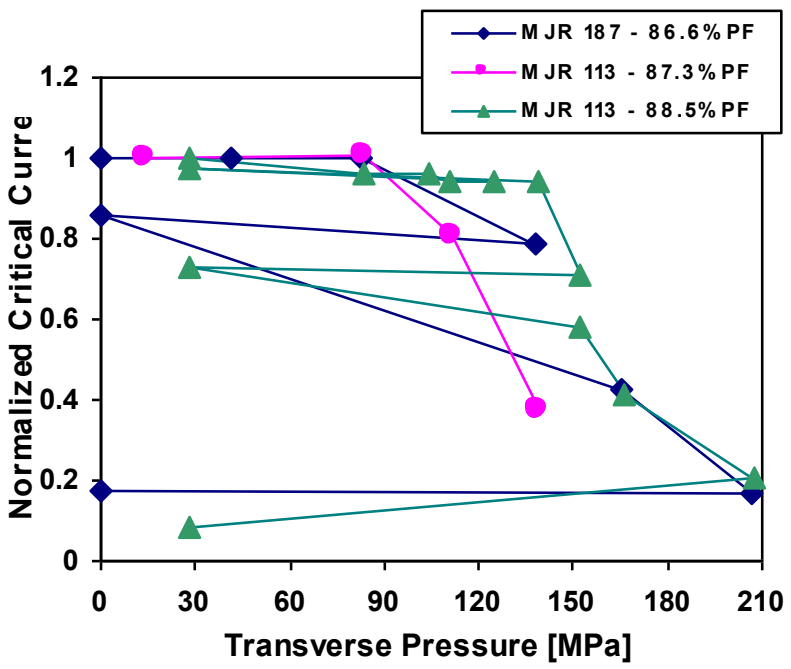

Fig. 5. Normalized $I_{c}$ vs. transverse pressure for the MJR samples at $12 \mathrm{~T}$.

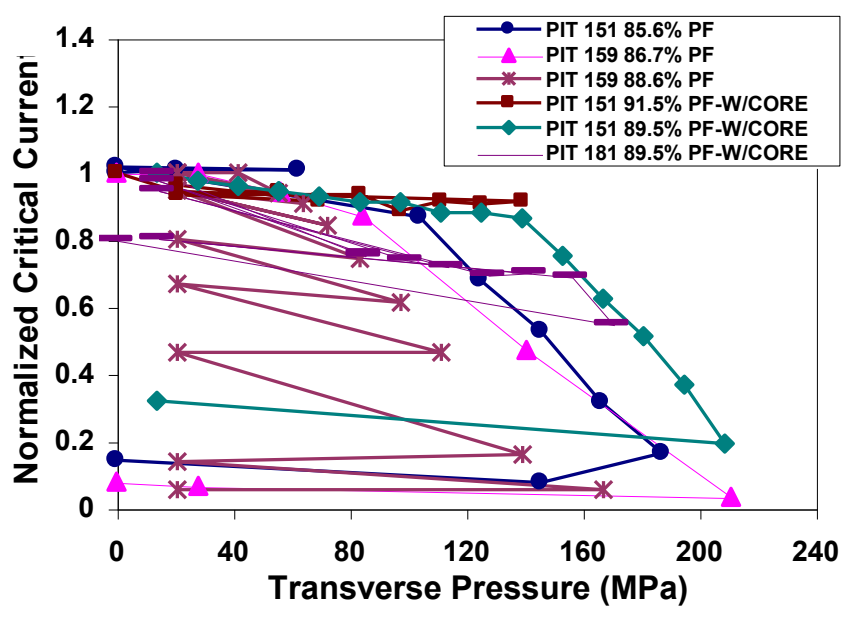

Fig. 6. Normalized $I_{c}$ vs. transverse pressure for the six PIT samples at $12 \mathrm{~T}$.

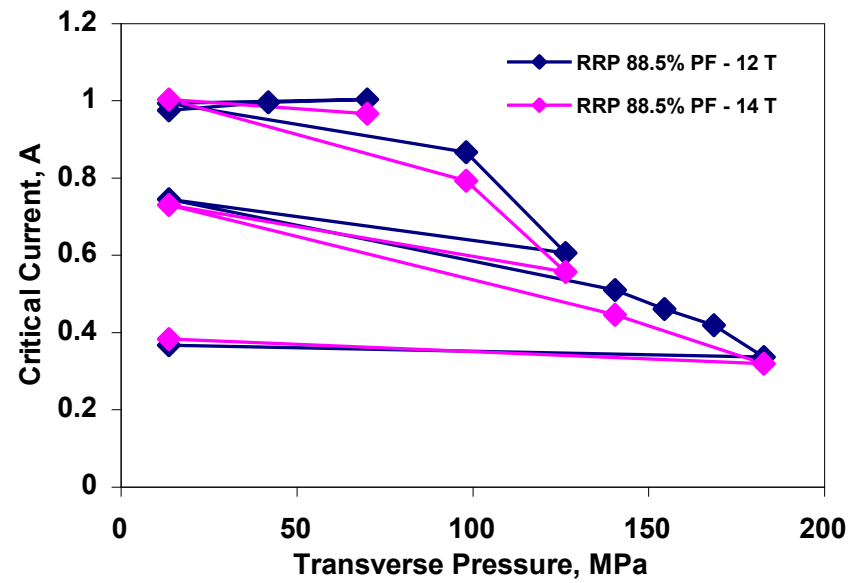

Fig. 7. Normalized $I_{c}$ vs. transverse pressure for the RRP sample at 12 and 14 $\mathrm{T}$.

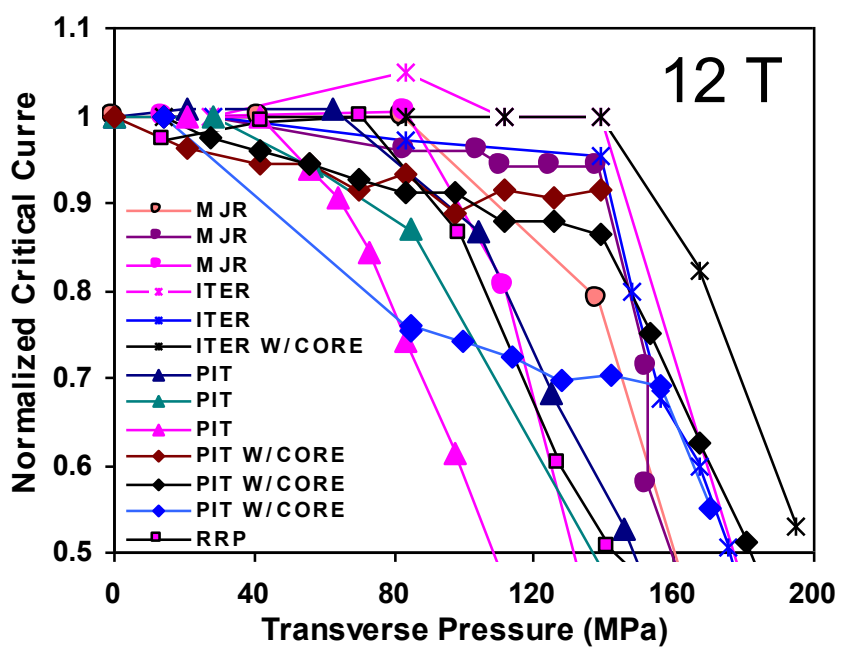

Fig. 8. Normalized $\mathrm{I}_{\mathrm{c}}$ vs. transverse pressure for all samples tested at $12 \mathrm{~T}$. 